\title{
PARÂMETROS PARA PRODUÇÃO DE ILUSTRAÇÃO: UMA ABORDAGEM METODOLÓGICA DOS PROCESSOS DE CRIAÇÃO.
}

Luiz Carlos Teixeira da Silva

Faculdade de Arquitetura Artes e Comunicação - UNESP

luiz@doisdi.com

Milton Koji Nakata, Dr.

Faculdade de Arquitetura Artes e Comunicação - UNESP

milton@faac.unesp.br

Resumo: $O$ presente trabalho tem o objetivo de abordar os aspectos metodológicos, característicos do Design, na produção de ilustrações. O texto não pretende ser profundamente técnico, nem apresentar regras rígidas para o processo de criação. Trata-se inicialmente de um olhar sobre a essência da ilustração e uma avaliação da atividade do ilustrador, no que diz respeito a seus principais exercícios como profissional. O trabalho ainda retrata a necessidade da utilização de uma metodologia de projeto, que deve ser estabelecida e moldada pelo próprio ilustrador. Baseando-se nas práticas normalmente utilizadas no Design, o ilustrador deve encarar a necessidade de criar ilustrações com uma visão projetual, fazendo com que seu trabalho passe por etapas cruciais objetivando um resultado de sucesso. Por fim, apresenta um projeto de ilustração que adota uma metodologia de projeto para atingir seu objetivo de forma eficaz.

Palavras-chave: ilustração, metodologia, criação.

Abstract: This article aims to address the methodological aspects, a characteristic od Design, in production illustrations. The text is not meant to be deeply technical nor present strict rules for the creation process. This is initially a glance at the essence of illustration and an assessment of the illustrator activity, with regard to the core activities as a professional. The article depicts the need to use a design methodology, which should be established and shaped by the illustrator himself. Based on the practices commonly used in the Design, the illustrator must face the need to create illustrations with a projectual vision, making his work pass through crucial stages aiming for a successful outcome. Finally, it presents an illustration that adopts a design methodology to achieve your goal effectively.

Keywords: illustration, methodology, creation. 


\section{INTRODUÇÃO}

A ilustração é um tema ainda controverso. Talvez por falta de compreensão real da sociedade, de muitos profissionais e também do mercado, a ilustração muitas vezes sofre consequências ao não ser adequadamente enquadrada em atividades como a artística, comercial ou industrial. É erroneamente, em diversos casos, tratada como uma forma gráfica de adorno ou retratada como uma produção de desenhos sem nenhuma finalidade específica.

Para aqueles que adotam a ilustração como atividade profissional, o sucesso no mercado de trabalho depende não apenas de seu empenho técnico. $O$ ilustrador deve se posicionar como agente propagador da boa conduta, do uso correto dos desenhos e, claro, mostrar que sua atividade depende de exigências técnicas e intelectuais. A necessidade, ainda existente, de esclarecer a essência da ilustração como atividade profissional pede que o ilustrador se instrua adequadamente de suas responsabilidades, inclusive de entender profundamente o que é ilustração.

George Hardie, renomado ilustrador e educador britânico, faz uma citação em Zeegen (2009), dizendo que ilustração é o "ato ou efeito de iluminar ou esclarecer um assunto". De acordo com a pesquisa levantada, podemos dizer que a ilustração explica, sintetiza, interpreta ou acrescenta informação através de imagem pictórica. Trata-se então de uma imagem que possui uma determinada função.

A ilustração acaba servindo como um canal que expõe diversos pontos de conexão com a mensagem que se deseja transmitir, mesmo que não haja linguagem verbal. Em livros e revistas, publicações onde as ilustrações normalmente são produzidas, servem como elementos essenciais para o projeto gráfico. A ilustração complementa e sugere ideias além do texto verbal. Sara Fanelli, escritora e ilustradora italiana, diz:

Se o texto é bom, é melhor deixar que as palavras descrevam e sugiram a imagem para o leitor e criar uma ilustração que mostre um detalhe menos óbvio ou que dê uma perspectiva visual inesperada ao texto. (ZEEGEN, 2009, p. 95).

O propósito desse trabalho é retratar as características da ilustração e como uma metodologia de projeto, assunto comum nas áreas do Design, podem beneficiar essa atividade. Pretende-se contribuir tanto no entendimento da profissão de ilustrador, quanto em seu exercício, fomentando o uso de métodos que objetivem o aumento do sucesso dos trabalhos desenvolvidos.

\section{BREVE HISTÓRICO DA ILUSTRAÇÃO}

Para entender melhor o tema e que ele se mostra intimamente ligado à atividade humana, é pertinente fazer uma abordagem de sua história. A ilustração está ligada às atividades do homem desde a antiguidade. Uma imutável característica é sua interpretação por sinais abstratos e leitura pictórica.

$\mathrm{Na}$ antiguidade, monumentos como o Código de Hamurabi e a Estela de Israel já utilizavam figuras ilustrativas. Mais tarde, com os papiros egípcios, a ilustração se tornou uma arte, culminando nas iluminuras da Idade Média, manuscritos religiosos em que a ilustração exercia seu papel de complementar a mensagem que o texto trazia, com o propósito de informar o leitor.

A partir dessa época surgiram novos meios de reprodução e aplicação da ilustração, envolvendo gravações em metal, madeira e pedra. A evolução da produção 
editorial aumentava o valor e a popularização da ilustração, já bem reconhecida pela sociedade.

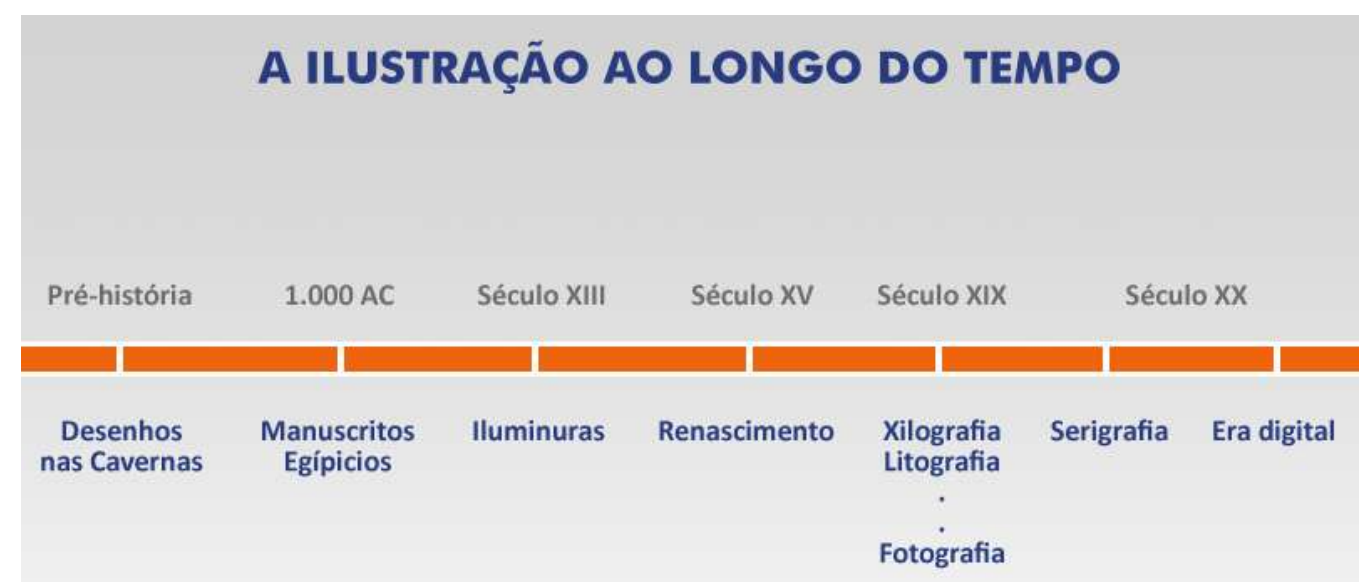

Figura 1 - Breve histórico da ilustração. Fonte: Elaborado pelo autor com base na pesquisa realizada (2016).

Foi no mundo editorial que a ilustração iniciou sua era dourada, por volta dos anos 20. Como força principal no design de página, as ilustrações estabeleciam uma maneira atrativa de propagar as ideias da época com revistas e pôsteres que retratavam estilo de vida, ficção e mensagens publicitárias.

Como determinadas funções, as ilustrações se tornam algo muito além do conceito de desenho. Seja para evidenciar algum ponto, esclarecer um determinado assunto ou tornar mais eficaz e prazerosa a leitura de uma publicação, a ilustração é fator decisivo na transmissão de mensagens.

Mesmo depois do advento da fotografia, que passou a ocupar grande parte do mercado editorial, a ilustração continuava como uma excelente alternativa. Devido à liberdade de criação e versatilidade de estilos, o uso da ilustração é reconhecido como uma ferramenta ideal em inúmeros projetos.

Atualmente, o perfil do ilustrador parece ter se cunhado na expressão livre e abstração, distanciando-se do primor na habilidade de desenho. Essa reavaliação da importância das habilidades ilustrativas fez com que houvesse uma ênfase no pensamento criativo. Certamente, pelo apelo comercial e desenvolvimento do mercado editorial, a preocupação com produção e design de página exigiu uma postura mais dinâmica e projetual.

\section{O TRABALHO DE ILUSTRAR}

A produção de uma ilustração, assim como acontece em outros projetos, deve passar por etapas que são essenciais para o sucesso do trabalho. Afinal, a ilustração deve desempenhar seu papel da maneira mais objetiva e clara possível e isso só pode ocorrer se o ilustrador encarar o processo com caráter projetual.

É importante lembrar que, cabe ao ilustrador entender sua responsabilidade profissional diante das necessidades sociais e comerciais. As exigências do mercado de trabalho algumas vezes colocam em prova a competência do ilustrador com anseios específicos. Seria justo para todas as partes, inclusive para o profissional, que seu trabalho procure sempre atender os envolvidos, buscando um ponto de interesse em comum, conforme Lupton (2008). 


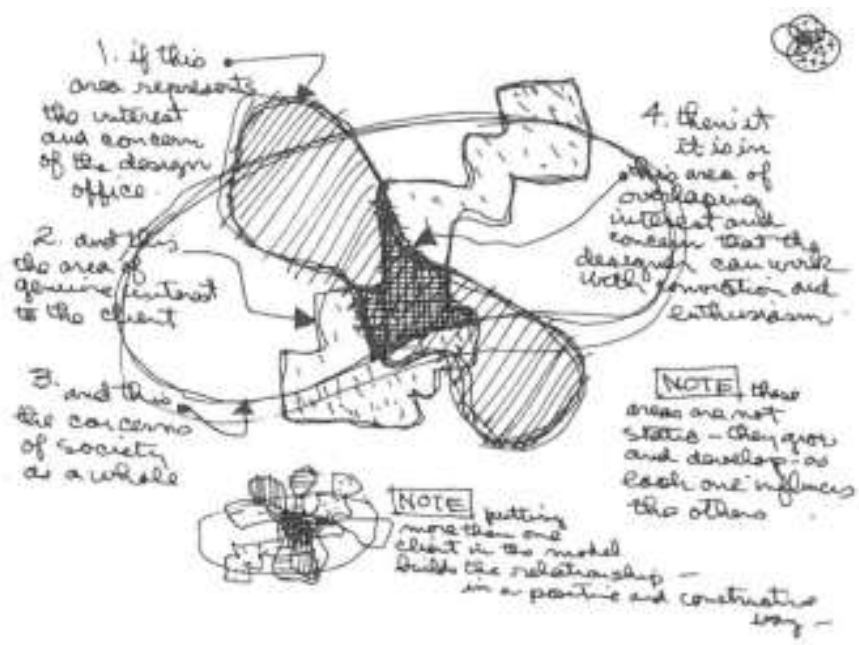

Figura 2 - Diagrama do designer Charles Eames, ilustrando o ponto de interesse em comum entre designer, cliente e sociedade, dentro de um processo de criação. Fonte: Lupton (2008).

Assim como no desenvolvimento de um produto físico ou mesmo como ocorre em projetos de identidade visual, uma ilustração deve ser produzida através de uma metodologia. Pontuando dessa maneira, é inevitável pensar em qual profissional está produzindo ilustrações. O designer ilustrador, que recebe em sua formação os conceitos metodológicos de projeto, não terá dificuldade em se adequar a metodologias para o desenvolvimento de uma ilustração.

No entanto, para o ilustrador que não é designer ou não possui as devidas orientações teóricas de projeto, se faz mais necessário o uso de um método que o auxilie na atividade.

\subsection{A ilustração como projeto: aplicação de metodologias}

A produção de uma ilustração, assim como acontece em outros projetos, deve passar por etapas que são essenciais para o sucesso do trabalho. Afinal, a ilustração deve desempenhar seu papel da maneira mais objetiva e clara possível e isso só pode ocorrer se o ilustrador encarar o processo com caráter projetual.

Em Design, diversas metodologias são aplicadas no desenvolvimento de um projeto. Munari (1981) diz que quando sabemos o que fazer e o modo como devemos proceder, o projeto se torna mais fácil. É necessário então um método que estabeleça etapas e regras para a produção, mas que isso não seja de forma alguma um bloqueio para o processo de criação.

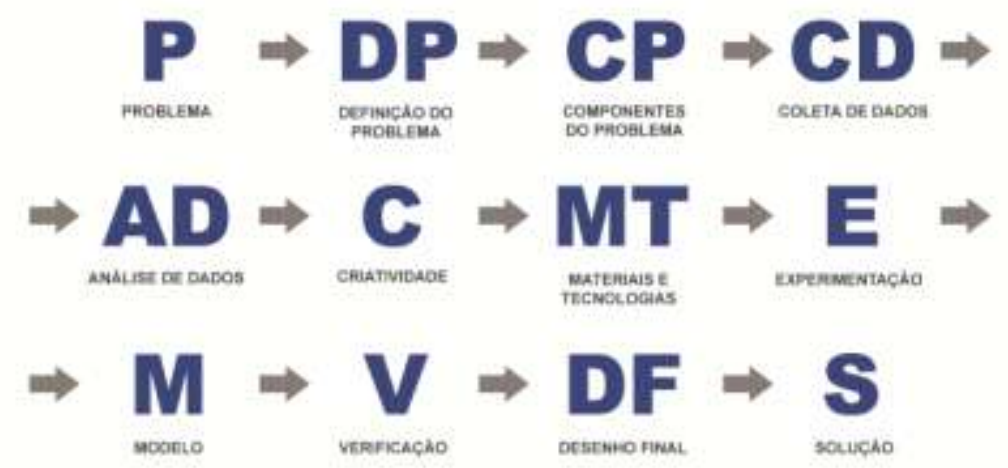

Figura 3 - Síntese de modelo de metodologia apresentado por Munari. Fonte: do autor, adaptado de Munari (1981). 
De acordo com Ambrose e Harris (2011), as chamadas etapas do pensamento fazem parte de um processo de design, transformando a necessidade em uma solução adequada. As etapas exigem um pensamento voltado para o projeto e para o usuário. É um sistema de criatividade, do qual o processo provém controle e direcionamento.

A metodologia não precisa ser algo absoluto e rígido, pois pode ser adaptada para melhorar o processo de criação. Aliás, cada ilustrador pode definir sua própria metodologia, apesar de que as etapas de definição de problema, pesquisa, criatividade, geração de alternativas e desenho final são muito adequadas e devem ser mantidas.

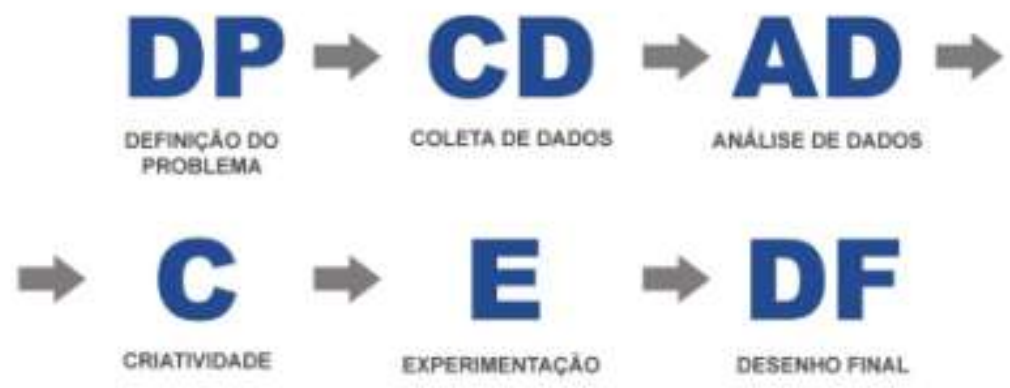

Figura 4 - Exemplo de adaptação de metodologia para a produção de uma ilustração. Fonte: Elaborado pelo autor com base na pesquisa realizada (2016).

Portanto, o desenvolvimento de uma ilustração deve ser iniciado com uma descrição do objetivo desse trabalho, seguido de um levantamento de ideias e requisitos e do entendimento de onde a ilustração será veiculada. Esse é o princípio da construção do briefing. Deve-se ainda complementá-lo com mais informações sobre o projeto, envolvendo dados sobre o cliente, prazos, estilo gráfico e público-alvo. A construção de um bom briefing garante ao projeto uma execução com mais chances de sucesso.

Inicia-se então a etapa em que as ideias para a ilustração devem ser geradas. É imprescindível que o contexto do projeto seja compreendido, desse modo, é necessário um levantamento do máximo possível de referências e informações sobre o tema da ilustração. Isso influenciará beneficamente no processo de geração de ideias.

A pesquisa pelas informações pode ser feita utilizando publicações sobre o tema, como livros, revistas e outros materiais impressos e digitais. O uso da Internet possibilita uma pesquisa mais eficiente, pois permite acesso a mais informações em menos tempo. A pesquisa não deve se restringir a uma única ideia ou palavra. É interessante que outros termos relacionados com o projeto também sejam pesquisados, levando o processo de levantamento de dados a um nível mais rico.

Painéis semânticos também podem ser utilizados como apoio na geração de ideias. Esses painéis podem ser compostos de imagens, amostra de cores, formas, texturas ou qualquer material visual que esteja relacionado com o projeto. Uma das principais vantagens desses painéis é que eles permitem experimentar visualmente as referências mais agradáveis, além de oferecer boa carga de inspiração no desenvolvimento das ideias para ilustração.

O surgimento de ideias pode acontecer a qualquer momento. Portanto é aconselhável que o ilustrador sempre tenha em mãos alguma ferramenta para geração de esboços. Os chamados pequenos cadernos chamados sketchbooks e aplicativos 
para desenho em dispositivos móveis são ideais para registrar as ideias, em forma de esboços. Desenhar e fazer anotações são atividades fundamentais para a geração de alternativas para a ilustração final.

O próximo passo do projeto da ilustração deve ser a etapa denominada brainstorming. Ela pode ser definida como uma produção em grande escala de ideias e alternativas, com o objetivo de definir a ilustração final. É interessante ressaltar que a prática de ilustrar pode fazer do ilustrador o único responsável pelo brainstorming e pelo resultado final.

Nesse momento, toda a pesquisa realizada e o levantamento de informações sobre o tema se torna mecanismo para a produção de alternativas gráficas. A exploração, a combinação e a distorção das ideias, pensamentos e significados concedem ao ilustrador a capacidade suficiente para a concepção de diversas opções. A experimentação de formas, cores e palavras também geram novas perspectivas para o trabalho.

Assim que as ideias mais promissoras estiverem definidas, é o momento de o projeto caminhar para uma linha mais definitiva. Portanto, é necessário escolher as alternativas com maior potencial de sucesso, reduzindo o número de opções ou mesmo escolhendo apenas uma delas para ser trabalhada. É preciso lembrar que o objetivo do projeto e as especificações do cliente sejam atendidos.

Faz então, a necessidade de uma composição gráfica para apresentação ou, pelo menos, para a apreciação própria do ilustrador. Desse modo, a construção gráfica pode ser avaliada com maior precisão e com um caráter mais conclusivo. Então, a estrutura visual final da ilustração se faz mais presente e necessária.

Durante todo o trabalho, o artista deve ter em mente o esqueleto estrutural que está configurando, enquanto, ao mesmo tempo, deve prestar atenção aos contornos, superfícies, volumes completamente diferentes que está realmente fazendo. $\operatorname{ARNHEIM~(2005,~p.~84).~}$

Cabe ao ilustrador, principalmente nessa fase, saber aplicar corretamente conceitos bastante trabalhados em design, para que a ilustração consiga realizar sua principal função, que é transmitir uma determinada mensagem. Assim como ocorre em projetos de design, conceitos regidos pela Teoria da Gestalt e pela Teoria da Cor também devem ser levados em consideração no desenvolvimento da ilustração.

Enfim, a apresentação do projeto finalizado possibilita resultados que servem como aprendizado para novos trabalhos. Os dados levantados após a apresentação e implementação podem, inclusive, serem usados no mesmo projeto, para devidas adaptações sugeridas pelas condições finais do trabalho. Esse retorno pode auxiliar o método, com informações inseridas em qualquer etapa.

Como síntese do levantamento bibliográfico e das atividades desenvolvidas no processo de criação de uma ilustração, podemos propor um método que pode se encaixar nas necessidades do ilustrador. Tais etapas correspondem aos principais estágios do trabalho de ilustrar, respeitando as necessidades do projeto já discutidas nesse capítulo. 


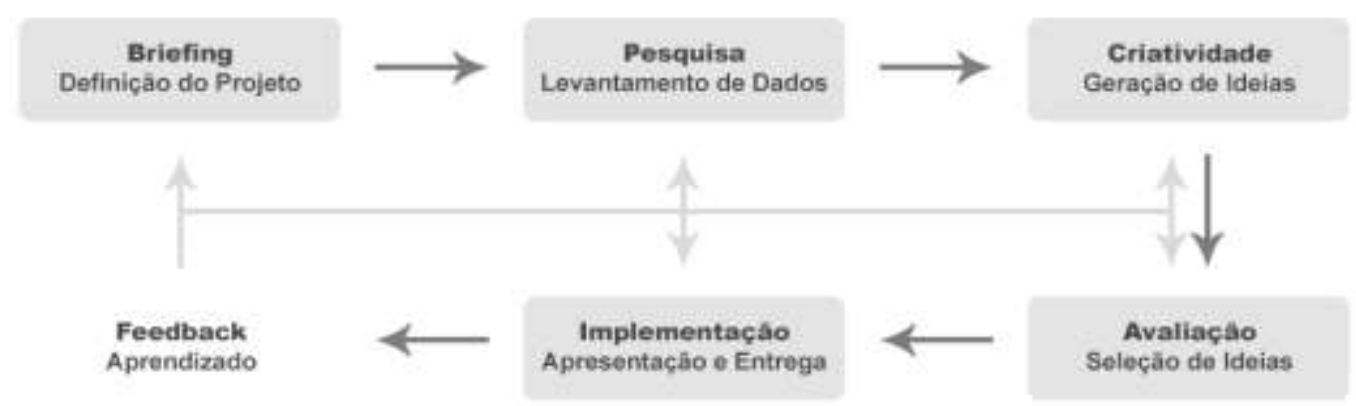

Figura 5 - Etapas de um processo de design para desenvolvimento de ilustrações. Fonte: Elaborado pelo autor com base na pesquisa realizada (2016).

Mesmo seguindo corretamente as etapas do projeto e construindo de forma adequada os elementos da ilustração, é muito provável que o trabalho necessite sofrer modificações. O ilustrador deve encarar isso de forma positiva e realizar as mudanças necessárias, claramente, sem abandonar o que o briefing estabeleceu para o projeto. Alterações que desrespeitam o projeto e distorcem aquilo que foi regido no início do desenvolvimento, são incabíveis e farão com que a ilustração certamente não atinja seu objetivo.

\subsection{As ferramentas do ilustrador}

A produção de uma ilustração, além de seu objetivo funcional, normalmente integra em sua essência um reflexo do uso de materiais e estilos. É um espectro que carrega mensagens cunhadas nas culturas sociais, que muitas vezes soam de forma inconsciente na leitura da ilustração.

O uso de determinadas ferramentas garante adição de algumas características singulares e interpretativas na produção da uma ilustração. O fato de produzir um desenho feito à caneta esferográfica sobre uma superfície ou área que simule um caderno pautado, claramente refletirá uma ideia de produção livre, jovial e até amadora, remetendo a desenhos que alunos rabiscam em seus cadernos nas escolas. Esse é apenas um pequeno exemplo da importância de conhecer materiais, ferramentas e técnicas para ilustrar.

Tratando da execução de um projeto, a escolha de matérias refletirá tanto na execução do processo, quanto no resultado final da ilustração. É claro que o trabalho de ilustrar não deve se restringir a um único tipo de material ou um grupo deles. O uso do lápis, por exemplo, é um recurso básico e essencial na produção de desenhos, principalmente nas etapas iniciais.

Cada ilustrador construirá seu próprio repertório de conhecimento de materiais e ferramentas para executar seu trabalho. Seja de modo convencional, utilizando ferramentas analógicas como lápis, pincéis, canetas, tintas e papéis ou utilizando os meios digitais, se apropriando da dinâmica de produção permitida pelos softwares. É fato que é sempre importante experimentar técnicas, ferramentas e materiais diferentes.

A busca pela originalidade, inclusive, acaba por levar o ilustrador a utilizar materiais não convencionais na produção de suas figuras. Há profissionais que ilustram utilizando resíduos diversos, comida, pedras, madeira entre outros materiais. Portanto, estar aberto a possibilidades é um caminho interessante para a prática do profissional da ilustração. 


\subsection{Apresentando a ilustração}

A respeito da apresentação do trabalho do ilustrador, esta deve expor sua capacidade produtiva e criativa. As plataformas de apresentação são variadas, inclusive no que diz respeito ao tipo de exibição que deve ser feita.

$\mathrm{Na}$ exibição do resultado final de um projeto para um cliente, dependerá basicamente de como este último precisa receber o projeto. Como forma de currículo, a melhor maneira é a construção de um portfólio. Essa compilação deve reunir os melhores exemplos de ilustrações feitas pelo profissional. Além disso, deve-se ter a preocupação em como os trabalhos serão apresentados a outras pessoas. Apesar de o tema envolver postura e outros assuntos relacionados à apresentação pessoal, esse trabalho não apresentará tais informações.

O ilustrador pode simplesmente ter seu portfólio de forma física, com uma seleção impressa e adequada de seus trabalhos. A qualidade da impressão e o tipo de papel influenciarão diretamente no julgamento do conjunto, portanto é necessário escolher corretamente uma gráfica e verificar as possibilidades de apresentação que ela pode oferecer.

Outra maneira de criar um portfólio é gravar um CD, DVD ou outra mídia similar com as imagens compiladas, de preferência, em uma apresentação. O fato de esse material ser mais compacto facilita seu transporte e distribuição. No entanto, ele sofre da desvantagem da dependência de algum dispositivo para leitura, impedindo sua apreciação imediata.

A melhor a alternativa é o desenvolvimento de um portfólio digital online. 0 mais indicado é a criação um site com domínio próprio e personalizado como plataforma personalizada. Existem ainda sites especializados na divulgação de ilustrações, que são ótimas opções para a montagem de uma compilação digital de trabalhos. Mesmo que o trabalho do ilustrador não seja digital, basta digitalizá-las utilizando scanner ou câmeras fotográficas. As grandes vantagens do portfólio digital online são a facilidade de manutenção, a grande capacidade de volume de informação, a maior possibilidade de divulgação e feedback rápido.

\section{NOS BASTIDORES: A CONSTRUÇÃO DE UMA ILUSTRAÇÃO}

Foi abordada nesse trabalho a importância da aplicação de uma metodologia ou processo de design no desenvolvimento de uma ilustração. Através de um método, os objetivos se tornam claros e o resultado tem mais garantias de sucesso.

A ilustração Behind the Scenes, do designer e ilustrador americano Jeff Szuc é um bom exemplo de um trabalho que passou por uma metodologia de projeto. A peça solicitada pelo Colégio Ithaca, de Nova lorque, necessitava ilustrar uma matéria para sua revista interna. O tema era "Nos bastidores da política" e os editores queriam uma ilustração que mostrasse a arena política e a dimensão da experiência de votação. Também era importante não ser satírico ou partidário.

Estabelecido o briefing o ilustrador iniciou sua pesquisa do tema e o desenvolvimento de ideias, que gerou de vinte cinco a cinquenta esboços, dos quais dois deles se mostraram promissores para a ilustração final. Houve uma preocupação em refinar essas propostas para fim de apresentação. 

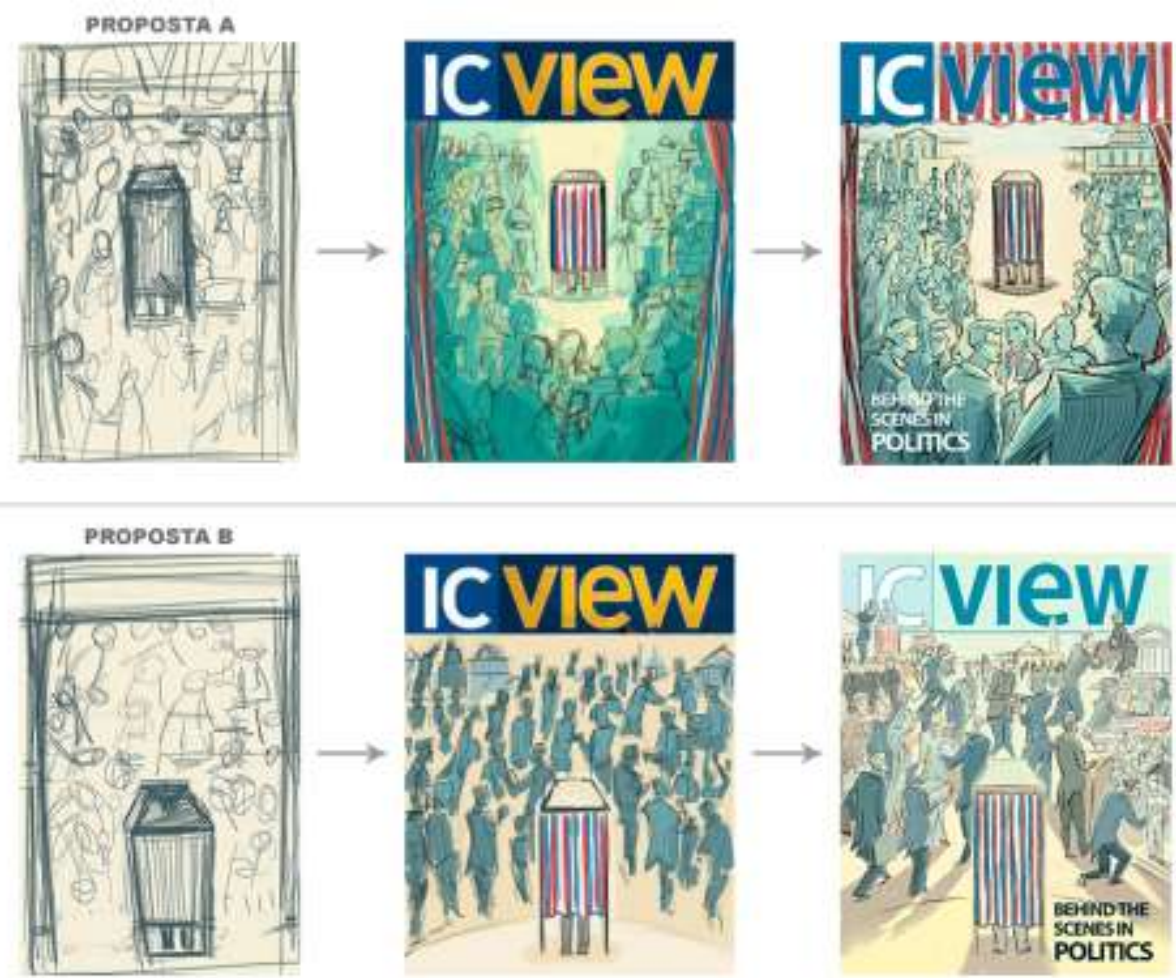

Figura 6 - Duas ideias em forma de esboço e seus respectivos refinamentos gráficos para fim de apresentação ao cliente. Fonte: Szuc (2012).

A partir da escolha e orientações do cliente com relação a algumas adaptações, o ilustrador iniciou o processo de construção do trabalho final, que acabou sendo uma espécie de amálgama das duas propostas apresentadas. Utilizando de meios digitais, a ilustração passou pelas etapas de definição das formas de seus elementos gráficos.

A proposta readaptada passou novamente pela avaliação dos clientes e, depois da aprovação final, o ilustrador pôde aplicar as cores de forma que determinados elementos fossem mais destacados que outros. É perceptível o fundo em tons mais claros, reforçando a perspectiva e distinguindo os elementos entre os planos. A ilustração foi finalizada respeitando o pedido do cliente e o briefing estabelecido, servindo adequadamente ao seu propósito.

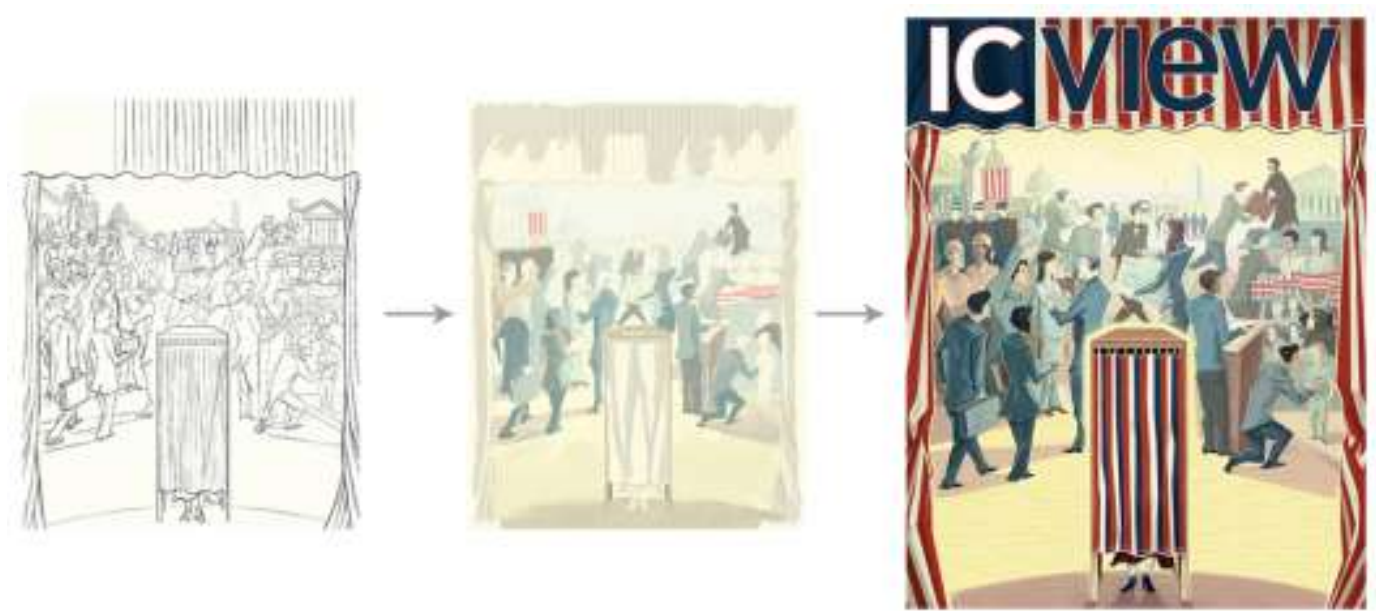

Figura 7 - Algumas etapas do desenvolvimento da proposta final, com a ilustração aprovada pelo cliente em sua forma finalizada. Fonte: Szuc (2012). 


\section{CONCLUSÃO}

A prática de ilustrar não é uma atividade leviana. A atividade profissional do ilustrador, ainda que não seja reconhecida justamente pela sociedade e até por profissionais de áreas correlatas, deve ser encarada com seriedade. Atualmente o uso da ilustração no mercado é alto e isso é realmente estimulante, principalmente para aqueles que desejam se iniciar como ilustradores profissionais.

É conclusivo que a postura do ilustrador não deve refletir uma aparência negligente e extremamente subjetiva. Faz-se importante o uso correto de métodos de criação, de desenvolvimento e também de apresentação. A criatividade é sempre muito importante, não somente na etapa de geração de ideias para uma nova ilustração. A inovação se faz necessária em todas as atividades do ilustrador, o modo como ele se comporta socialmente, a escolha de uma metodologia adequada de trabalho, o uso criativo de materiais e ferramentas e o modo como seu trabalho é apresentado e absorvido por outras pessoas, comercialmente ou não.

Desse modo, o uso de um processo de design na produção de ilustrações se torna crucial para o sucesso do profissional e para os anseios sociais e comerciais. 0 método não deve ser visto como influenciador negativo no processo, mesmo que as etapas pareçam prolongar o tempo de desenvolvimento. A metodologia aplicada beneficia inclusive a apresentação da ilustração, pois além de ser mais objetiva, carrega consigo valores que foram agregados durante as etapas do projeto.

\section{REFERÊNCIAS}

AMBROSE, Gavin; HARRIS, Paul. Design thinking. 1 ed. Porto Alegre: Bookman. 2011.

ARNHEIM, Rudolph. Arte \& percepção visual: uma psicologia da visão criadora. 2 ed. São Paulo: Livraria Pioneira Editora. 2005.

CAPLIN, Steve; BANKS, Adam. 0 essencial da ilustração. 1 ed. São Paulo: Editora Senac São Paulo. 2012.

DONDIS, Donis A. Sintaxe da linguagem visual. 1 ed. São Paulo: Livraria Martins Fontes Editora Ltda. 1991.

EDWARDS, Betty. Desenhando com o lado direito do cérebro. 4 ed. São Paulo: Ediouro. 2002.

FARINA, Modesto. Psicodinâmica das cores em comunicação. 2 ed. São Paulo: Edgard Blucher. 1982.

HURLBURT, Allen. Layout: o design da página impressa. 1 ed. São Paulo: Nobel. 2002. LUPTON, Ellen; PHILLIPS, Jennifer C. Fundamentos do design. 1 ed. São Paulo: Cosac Naify. 2008.

MUNARI, Bruno. Das coisas nascem as coisas. 2 ed. São Paulo: Martins Fontes. 2008. NAKATA, Milton K; SILVA, José Carlos P. Desenho para design. 1 ed. Bauru: Canal 6 Editora. 2011.

NAKATA, Milton K; et. al. Ensaio em design: arte, ciência e tecnologia. 1 ed. Bauru: Canal 6 Editora. 2010.

SZUC, Jeff. The behind the scenes, illustration process. 2012. Disponível na Internet por http://jeffszuc.com/illustration/the-behind-the-scenes-illustration-processtutorial. Acesso em jun. de 2014.

ZEEGEN, Laurence; CRUSH, C. Fundamentos de Ilustração. 1 ed. Porto Alegre: Bookman Companhia Editora. 2009. 